\title{
Sustainable Energy Development Using Space- Based Solar Power in Indian context
}

\author{
Meghna Bhagat ${ }^{*} \oplus$, Rosewine Joy ${ }^{1}$
}

School of Management, Presidency University, Banglore, India

* Corresponding Author (meghna9230@gmail.com)

Received: 29 August, 2021

Revised: 10 October, 2021

Accepted: 10 November, 2021

Published: 25 December, 2021

How to cite this paper:

Bhagat, M., \& Joy, R. (2021).

Sustainable energy development using space-based solar power in Indian context. Quest Journal of Management and Social Sciences, 3(2), pp. 256-264.

Copyright (C) 2021 by authors and Quest Journal of Management and Social Sciences.

This work is licensed under a Creative Commons Attribution-Non Commercial-No Derivatives 4.0 International License.

https://creativecommons.org/

licenses/by-nc-nd/4.0/

\section{Abstract}

Background: Progressive degradation of the environment due to the intervention of humans in the natural processes brought into light the need and the concept of sustainable development. The three pillars of sustainable development are Economic, Social, and Environmental. Sustainability has become one of the important tools to overcome the threats and is the dire need of the hour. This paper illustrates the detailed concept of Space-based solar power (SBSP) which defines the collection of solar energy in outer space and directing it towards the earth using electromagnetic waves. The edge of collecting solar power from space and not by the conventional methods include the strong collection rate and improved collection period. This is mainly because of the absence of the earth's atmosphere that consists of a lot of external impurities and the decreased effects of reflection and absorption on solar energy on its way to earth.

Objective: To put forward the importance of the use of space-based solar power system in India and to establish how space-based solar power is one of the answers of sustainable energy development for a better future for the country.

Method: The study is based on secondary data. The findings indicate the need for sustainable energy development and the effective use of space-based solar power which would answer to the never-ending demands of human beings.

Result: The article also delineates the opportunities of space-based solar power as well as the challenges that might be faced while building the system.

Conclusion: The paper is a descriptive and conceptual study which illustrates SBSP as an innovative and important breakthrough in the field of science and one of the most important topics of discussion that needs to be addressed. The paper suggests the need for conducting more study on the topic and development of projects to measure its feasibility in the future, in terms of Indian context.

Paper Types: Research Paper

Key Words: Sustainable energy development, Space-based solar power, Solar panels, Zero emission, Sunlight

JEL Classification: O33 


\section{Introduction}

The word sustainable means the utilization of the natural products and energy in a way that does not cause loss to the environment as well as maintaining it at a certain level so that the future generation can avail the same opportunities as we are (J \& Majid, 2020). Sustainable energy development states the utilization of innovations and technological developments in amalgamation with the concept of sustainability for a better future. One of such interesting developments in the process is the concept of using Space-Based Solar Power for generating electricity in large quantities. With the increase in human population and demands of human beings, sustainable energy development is the dire need of the hour.

The conventional use of solar panels has become common now. The countries in the tropical region have already adapted to it. A photo-voltaic (PV) module captures sunlight in the form of solar energy which is used to generate direct current electricity. There are few problems associated with traditional solar panels which are in use at present that need improvements. Few such problems are, it can be used to capture sunlight only during daytime as seen in the Duck Curve. A Duck Curve depicts the power production over the course of a day including the timing imbalance between peak demand and renewable energy production graphically. (Mankins J. C., 1997). During cloudy and rainy days there is an effective drop in the amount of solar energy received. About $30 \%$ of the total solar energy is lost due to scattering and by the reflection of clouds and the earth's atmosphere. More than $23 \%$ is absorbed by the different gases present in the atmosphere. The need for producing a large quantity of electricity requires more solar panels which would require a lot of space. Such big rooftops and yards are hard to build. There are some percentages of emission of greenhouse gases in the environment while transportation and installation of solar systems.

To overcome these issues, the alternative answer is the use of space-based solar panels. Our Sun is the largest known and unlimited (for the time being) energy resource in the entire solar system. In the vicinity of Earth, every square meter of space gets about 1.366 kilowatts of solar radiation, but when it touches the surface of the earth, it reduces because of atmospheric absorption and scattering; weather; and summer, winter, and day-night cycles to less than an average of 250 watts per square meter (National Security Space Office, 2010). Many pieces of research are being conducted every year to know about the feasibility of space -based solar power and the time required to make it a success. Moreover, as mentioned before, the World energy demand is significantly increasing and to satisfy this demand, it is important to move on to a source that would generate the required amount of energy needed for the increasing population. Sun radiates about 2.3 billion times more energy than what hits the periphery of the Earth, which itself is more energy in an hour than all human civilization directly uses in a year, also it will carry on producing free energy for billions of years in future. Space-Based Solar Power is the use of solar panels which would be set up in the lower orbit of the earth or in GEO (geosynchronous Earth orbit) to collect this solar energy in space and then transmit it wirelessly to the receiving station on the earth. Space-based solar energy has the potential to address the global energy security and greenhouse gas emissions challenges. According to the National Security Space Office's Advanced Concepts, space-based solar power has the potential to provide not just energy security but economic, intellectual, environmental, and space security as well. The electromagnetic beam of light will be dispersed over a huge array thus, the birds and aircrafts will not be affected from it (Wood, 2012). There have not been many studies done on the concept yet, but ISRO found it as an important mission to start working on in near future. The concept is still on papers in case of India which needs effective practical probing as mentioned by Sivan, Chairman, Indian Space Research Organization and Secretary, Department of Space, in 2018. India lacks in terms of practical work when compared to other countries like China, Russia and the USA. Many people are still unaware of the concept, thus 
this paper will throw some light on the concept and its importance which would interest the readers to gather more information on the same. This is mainly since the concept is not frequently talked on. The concept shows good prospects keeping in mind about the depleting energy resources and the problems of using other forms of resources in the country. The objectives of this research can be summarized as to establish the limitations of ground based solar panels simultaneously introducing the idea of space based solar power as an alternative and the challenges and opportunities of space based solar power in India.

Further part of this study is organized as: second section review the literature followed by research methods in section three, data analysis and results are made in section four and section five concludes the study.

\section{Review of Literature}

\section{What has been done till date?}

The concept was first published in the year 1941 by a science fiction writer Isaac Asimov in a short story named "Reason". The serious work was done by Peter Edward Glaser, a Czechoslovakian-born American scientist, in this paper "Method and Apparatus for Converting Solar Radiation to Electrical Power" for which he received a patent (Patent Number - 3,781,647) in the year 1973. In his paper, he stated the transmission of solar power over long distances with the use of microwaves to large earthbased receivers called Rectenna (U.S Patent No. 3781647, 1973). In the 1970s, NASA along with the US Department of Energy (DoE) spent about \$20M to study the feasibility of the project which resulted in the establishment of the concept and a reference $5 \mathrm{GW}$ architecture was proposed. The design did not pass the economic requirements due to the availability of cheaper alternatives present at that time. In 1995-97 NASA again started studies on the concept under the initiative named "Fresh Look". It was concluded from the study that Space solar power would become a vital candidate among the other options for facing the energy demands of the 21st century (Mankins J. C., 1997). In the year 2007 US National Security Space Office even conducted a thorough study on the feasibility of the concept. In 2008, Japan put forwarded its Basic Space Law which developed space solar power as a national goal, and in the year 2009, Pacific Gas \& Electric and the Japan Aerospace Exploration Agency (JAXA) proceeded ambitious plans for the development of the project. In 2010, the Indian Space Research Organisation jointly with the US National Space Society laid the preliminaries for the space-based solar power program named Kalam - NSS Initiative. In the year 2011 the International Academy of Astronautics (IAA) came up with its highly detailed study under the name "First International Assessment of Space Solar Power". They stated that "There are no fundamental technical barriers that would prevent the realization of large-scale SPS platforms during the coming decades" (Mankins \& Kaya, The First International Assessment of Space Solar Power: Opportunities, Issues and Potential Pathways Forward, 2011). They also highlighted the most viable the architectures that will be discussed in this paper as well.

\section{Performances by other countries}

In the year 2012, China proposed collaboration with India in the field of space for the mission of SpaceBased Solar Power initiative that could be done through long-term bonding with appropriate funding. On 12th March 2015 JAXA declared that they have wirelessly transmitted 1.8 kilowatts to a small receiver for 50 meters by converting electricity to microwave and again back to electricity (Tarantola, 2015). China has planned to launch small solar satellites into the stratosphere between 2021 and 2025. The country has even planned to generate 1 megawatt (MW) of energy by 2030. By 2050 they have planned to develop commercially viable solar-based power plants (Goswami, 2019). 
United States, at first, suspended the proposed SPS in the 1980s due to the massive initial investment to be incurred by the government and the technology was not so advance during that time. Later, in 1990s NASA restarted the study under the guidance of J.C Mankins (Oda, 2004). At present the country has been researching developing a reusable launch system to lower the costs and improve the SBSP system. Even Space X plays an important part here in the development. They have gone into partnership with Northrop Grumman to advance the technology. The Space Solar Power Initiative having a fund of \$17.5 million aims to develop space-based solar power at a cheaper cost with improved technology. NASA has already developed a model named SPS ALPHA 2012 version (Mankins J., SPS-ALPHA: The First Practical Solar Power Satellite via Arbitrarily Large PHased Array, 2012) in order to determine the feasibility of the project. Japan has done experiments to state that the transmission of electricity using a microwave is possible. They have made space-based solar an important upcoming project in their future space exploration portfolio. They have included two conceptual designs - SPS2000: a low Earth orbit (LEO)-based constellation providing constant power to ground stations and SPS2004: a GEO-based satellite with rotating solar collection mirrors (National Space Policy Secretariat, Cabinet Office, 2020).

Russia had stated in the late 1980's that it was planning to use satellites to accumulate solar energy and to illuminate it back to Earth. Instead of microwaves, Russian systems will use infrared lasers scattered throughout the panel, with the aim of combining their radiation to make laser beams strong enough to transmit electricity to Earth. (Broad, 1987). The European Union supports long-term research into the possible delivery of an operative system for many years away. Solspace (scheduled for December 2020 to November 2025) includes large, lightweight solar-powered displays on solar-powered farms around the world (European Research Council). India has been exploring SPS concepts for a long time ago, seeing technology as essential to a "massive public journey", it has been made a part of "World Space Vision 2050" (Kalam, 2013), but needs serious probing keeping in mind the present scenario of the country and its demands.

\section{Research Methods}

\section{Data collection techniques}

The paper is based on secondary data and secondary sources for information. A qualitative method of study has been followed to study the different journals and articles extensively, available on the internet and the documentaries related to the topic. The paper has been developed by selecting articles based on the well-known publications along with the quality of insights shared about the topic analyzing the facts and research done in the past. It discusses about the problems associated with traditional solar panels in details, thus pointing out the significance of space based solar panels. The paper illustrates the different architectures of the model suggested by IAA by studying them qualitatively. Data analyzation has been done on the power consumption of the country from the data available in the government's official sites. Later, the paper includes the different opportunities and challenges existing pertaining to the topic of discussion of our study. The topic that is being discussed has been emerging every day and not known by many people around which shows the existing gap in the society.

\section{Duration of the study}

For this paper, our focus for collection of data was secondary resources available on internet, magazines, and journals for the period from 2011 to 2021. The data collected have been analyzed in detailed to form the conclusion suggesting the opportunities and the challenges to be faced while implementing the concept in real. 


\section{Conceptual Model}

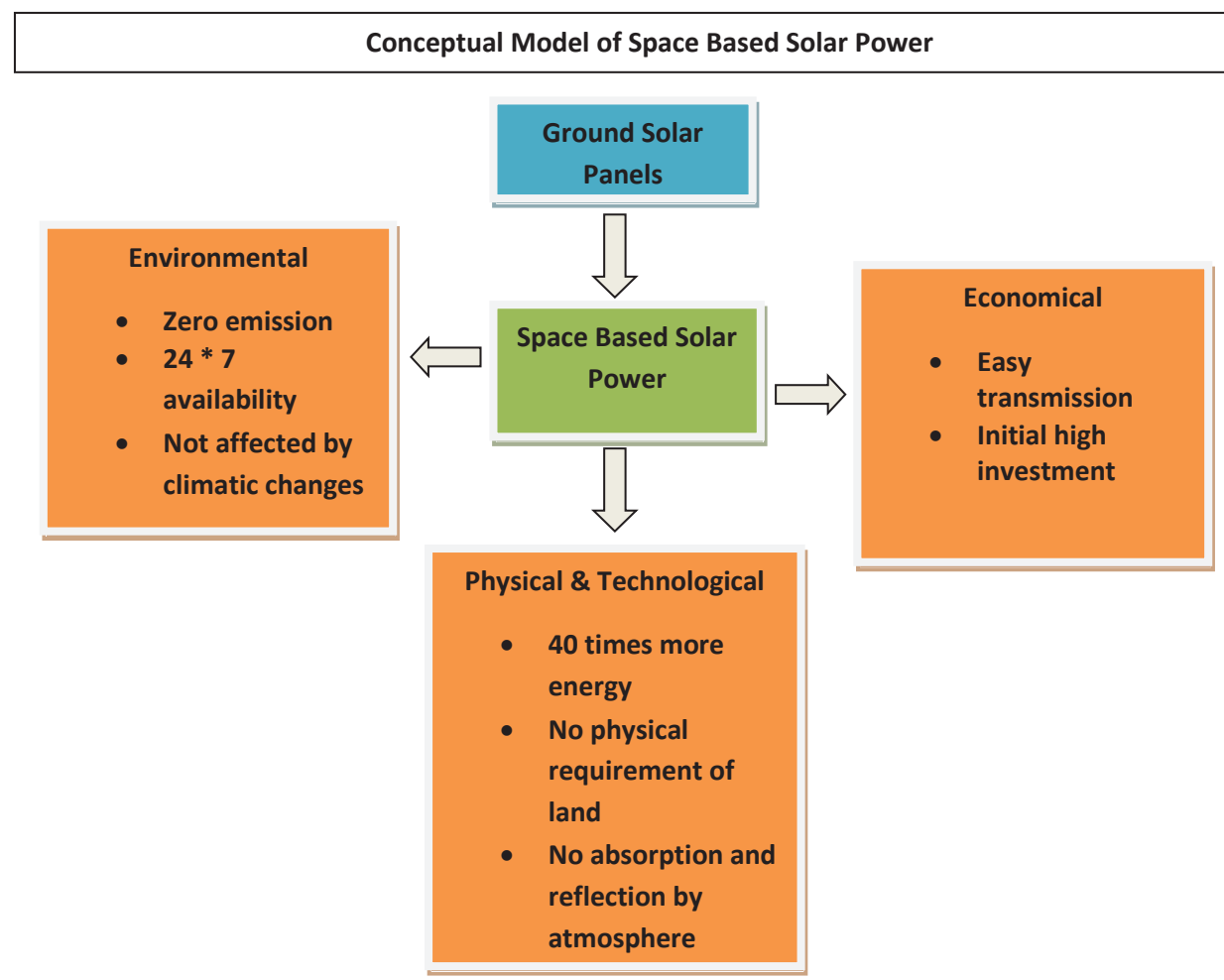

\section{Data Analysis and Results}

\section{Present Indian Scenario}

India ranks the world's third largest producer as well as the world's third largest consumer of electricity. With the passage of time there has been an increase in the consumption of electricity. The main source of electricity in India is coal apart from the other sources that include renewable, non-renewable and nuclear power. In the fiscal year 2018-19, India accounted about three-quarters of its total electricity produced using coal as the main source (Lolla, Yang, \& Vats, 2021).

There has been an overall increase in the consumption of electricity for the past ten years (Power, 2021). The total production for the FY2019 was calculated to be 1598 TWh (Central Electricity Authority, 2020). The share of fossil energy was $79.8 \%$. The world is moving fast towards digitations which need devices that work on electricity. The introduction of EV cars will increase consumption even more in the future. The extent to which we are over-utilizing our natural resources (Fossils), a time soon will come when we will be left with nothing. The reserve to production ratio calculates the number of years a resource can last if it is used at the same present rate. The data on Reserve to Production ratio available in Statistica 2021 shows the coal reserves might last only for 77 years in the case of Asia.

Moreover, the greenhouse gases emitted while producing electricity from coal are another major issue to solve. The power sector is accountable for half of India's CO2 emissions. It is also responsible for over 50 percent sulfur dioxide (SO2), 30 percent oxides of nitrogen (NOx), about 20 percent particulate matter (PM), among the other human-made emissions in the country. The producers are being advised by the Ministry of Environment and Forests to set up flue gas desulphurization devices in their plants 
to check the emission rates but most of them did not install them yet. From a survey conducted by the International Energy Agency in the year 2021, it has been found that the power sector is the one that generates the maximum percent of the polluting agents in the air.

As mentioned above, the energy produced from non-renewable resources does not have the same share as renewable resources. The percentage of solar energy is even smaller. India's installed solar power capacity was 39,083 MW as of 28 February 2021 (Energy., 2021). Apart from the normal installation of solar panels on land, the other form is practiced is the rooftop power-generation system connected via a local grid. This system also needs a boost when compared with the developments done in other countries. For an instance, India had only $430 \mathrm{MW}$ of solar roof (residential), while the UK with about half of the total capacity that of India had more than 2,500 MW of solar energy in 2018. Greenpeace has urged India to adopt a solar energy development policy as part of its integration into renewable energy for the benefit of more people. As things stand, solar energy accounts for less than $4 \%$ of India's electricity production, and coal is close to 70\%, mentioned in Indian Energy Outlook 2021.

Apart from the previously mentioned problems associated with conventional solar energy production, there are two more issues that account for the major challenges for India.

a. Availability of land - It requires quite a lot of land to produce huge amounts of electricity from solar power. With standard solar installation, the thumb rule states that for every $1 \mathrm{~kW}$ of solar panels required, the necessary area is approximately 100 square feet which means to generate $1 \mathrm{MW}$ of power, the requisite area of land is almost 2.5 acres or 1,00,000 thousand square feet. India is trying to achieve about 450Gigawatt (GW) of installed renewable energy by 2030 of which about $280 \mathrm{GW}(60 \%$ of the total) would come from solar. Moreover, there can be places that do not get the required amount of sunlight needed to produce the power.

b. Less efficient with increasing temperature - The solar panels can withstand high as well as cold temperatures, but their efficiency gets affected. The optimum temperature for maximum efficiency is 25 degrees Celsius (77 degrees Fahrenheit) at Standard Test Condition. After this point, with every increase per degree, the efficiency tends to fall by $10-25 \%$. For example, the coefficient of solar panel temperature can be $-.258 \%$ for each 1 degree Celsius. Therefore, at all temperatures above $25^{\circ} \mathrm{C}$, the maximum energy of the solar panel falls by $.258 \%$. India being a tropical country faces adversities of high temperature across its region. So, this might affect the power generated from the rooftop or ground solar panels.

An analysis has been done to illustrate the current electricity consumption in India. We have also shade light on the problems faced due to the use of conventional sources of electricity production.

\section{Opportunities and Challenges}

\section{Infrastructure and Physical Dimension}

At first, let's discuss about the different architectures of space-based solar power which are feasible in nature. At last, the opportunities and challenges of using space-based solar power have been discussed.

Architectures of the models proposed

IAA proposed three models out of many feasible studies. Each of the models has its advantages and disadvantages. For all the models put forward, three elements are common to conduct the whole process of receiving and transmission. The three elements being -

a. A receiving platform, to receive the solar energy from the sun

b. A transmission medium, to transmit the energy to the earth

c. Receiving station on earth to receive the energy. 
For the models proposed, the first two elements change according to their architecture, the working principle remains the same.

A. Microwave-Based Transmission (SPS Type I): In this type, very large PV (Photovoltaic) panels would be set in the lower orbit of the earth to receive the solar energy from the sun, coupled with a microwave power transmission system. This idea was first developed in the year 1979 by NASA and the US Department of Energy (DoE) in the project named Solar Power Satellite Reference System.

The construction of the system requires a large, stabilized platform that would rotate on three axes to keep its solar panels pointed towards the sun. The panels will receive the energy, then convert it into electricity and transmit it back to the earth in form of a microwave. The reason for using electromagnetic (laser) beam is since the dispersion of radiations can be minimized (Abdel-Hadi, 2020). It will be received by devices called Rectenna, which will convert the electromagnetic wave into direct current. There are certain problems associated with this such as the efficiency of the model, single radiation element design which needs more research.

B. Laser-Based Transmission (SPS Type II): This type also uses very large PV (Photovoltaic) panels to receive solar energy. The receiving and converting into electricity is the same as SPS I. The difference lies in the transmission process which is done using multiple laser beams functioning in the near-visible part of the spectrum instead of microwaves. They are targeted to a photovoltaic Rectenna on earth. Electric lasers proved to be more effective than solar pumped lasers for transmission. The architecture could be an integrated platform with multiple laser installations or a constellation of single laser satellites.

C. Mirror-Based Transmission (SPS Type III): This is quite different from the previous two models. It is established on a symmetrical optical concentrator that does not require huge PV panels. Thus, the problem of carrying large PV panels can be avoided in this model. Here, mirrors of few kilometers across are used to reflect the sunlight onto much smaller PV solar cells. After this, the energy is converted into electricity which is then sent to earth by a single microwave link. The model needs less complicated power management and distribution arrangement than the previous models. The mentioned reasons make this model most viable to construct among others.

It has been estimated that the system can produce 40 times more energy generated annually than conventional solar panels on earth. Space-based solar panels can produce 2,000 gigawatts (GW) of power persistently. The other problem is the size of the system, which is about $10.5 \mathrm{~km}$ long, $5.3 \mathrm{~km}$ wide or having a mean measurement of $56 \mathrm{sq}$. km (Sangeeta DebBarmana, 2020), thus, the chances of getting hit by space debris such as asteroids or meteors become more due to the increased surface area.

\section{Economical}

The foremost challenge is the cost of the system. The cost is evaluated to be about 100 times higher to compete with present utility costs. The cost of sending the whole system into space using space shuttle launches is very expensive. It has been calculated that for $6.5 \mathrm{~kg} / \mathrm{kW}$, the cost to place a power satellite in GEO (geosynchronous Earth orbit) cannot exceed \$200/kg to keep the power cost competitive. The maintenance of space-based solar panels is not as easy as ground solar panels. It requires telerobotic facilities to do the tasks. That again is costly. Though with the technological upgradation, the cost of satellites is going down gradually due to the use of reusable satellites. The power received can be easily transmitted to the end users across the globe making cheaper distribution of energy on ground. Thus, in future, the system might become feasible economical. 


\section{Environmental}

The system does not produce any greenhouse gases i.e., it has zero-emission. There is no loss of solar energy due to reflection and absorption as in the case of solar panels on earth. Unlike the solar panels on earth which can generate only during daytime, space-based solar systems can produce energy 24 hours, throughout the year because it is always solar noon in space. It is not affected by cloudy or rainy days. It will produce energy from a source that is available in abundance. It is a better alternative than nuclear power plants where removing nuclear waste is a big issue and uranium sources are limited. It is an alternative to fossil fuels which is limited source of energy (DebBarman, Gupta, \& Das, 2020).

\section{Conclusion}

Some amount of energy is lost due to the multistage conversions from photons to electrons and then into photons and at last again into electrons which can be reduced with more probing into the system. The GEO is mostly used for telecommunication purposes and not much space will be available for the system to function which can be an issue and requires proper planning before launching the system.

It can be understood that we cannot depend on coal for energy production forever. A time is soon to come when we will face the crisis. Moreover, the pollution caused is another issue to address keeping in mind the increasing rates of global warming. Over the coming years, with the advancement in technology, millions of Indian households would be buying new home appliances, air conditioning units, and electric vehicles. India would soon become the world's most populous country, adding the equivalent of a city the size of Los Angeles to its urban population each year. In order to meet the growing demand for electricity over the next two decades, India will need to incorporate a European Union equivalent energy plan into what it currently has. The demands will burden the need for more energy production. To meet the demands, we need to look for some other sources to continue the same living styles. There are many other forms of renewable resources available. But they are limited in their ability to provide for the energy needed to develop global industrial development and prosperity, due to land and water needs. According to the studies done, SBSP is an innovative and important breakthrough in the field of science that can fulfill the never-ending demands of human beings. The project has many challenges to overcome to make it feasible, but it can do wonders if we can probe more into the factors to make it a success. That requires some years of research, but it is the future of our country as well as of the whole world.

At the 32nd International Space Development Conference (ISDC), Dr. APJ Abdul Kalam, while giving his acceptance speech where he received the Wernher Von Braun Memorial Award in San Diego, USA said the importance of harnessing space-based solar power and how it can change the face of the world. In a seminar held in Coimbatore in the year 2012, he said that there is a rising possibility of using energy from space through space-based energy systems. Space-based solar power has many advantages over traditional ground based solar panels and India can play a very important role in this field. SBSP has emerged as one of the serious topics that need more attention. We have reached a point where India as well other countries should start conducting more studies on this field and develop a space-based solar power to meet the requirements of their people. The paper recommends that India should organize constructively to permit the development of SBSP and would be able to analyze the different paths available to resolve the remaining unknowns.

\section{Conflicts of Interest}

Author(s) declares no conflict of interest. 


\section{References}

Abdel-Hadi, Y. A. (2020). Space-based solar laser system simulation to transfer power onto the earth. NRIAG Journal of Astronomy and Geophysics, 6.

Broad, W. J. (1987, June 14). Soviet Studies Satellites to Convert Solar Energy for Relay to Earth. New York Times.

Central Electricity Authority. (2020). Growth of Electricity Sector in India from 1947-2020.

DebBarman, S., Gupta, S., \& Das, O. (2020). A Review:Space Based Solar Power(SBSP) in development of Smart city. International conference on Recent Trends in Artificial Intelligence, IOT, Smart Cities \& Applications (ICAISC-2020), 4.

Energy., M. o. (2021, March 31). Physical Progress. Retrieved June 15, 2021, from Ministry of New \& Renewable Energy.: https://mnre.gov.in/the-ministry/physical-progress

European Research Council. (n.d.). Enhancing Global Clean Energy Services Using Orbiting Solar Reflectors. Retrieved June 18, 2021, from cordis.europa.eu: https://cordis.europa.eu/project/id/883730

Glaser, P. E. (1973). U.S Patent No. 3781647.

Goswami, D. N. (2019, April 25). “China in Space: A Strategic Competition?”. Retrieved June 15, 2021, from www.uscc.gov: https://www.uscc.gov/sites/default/files/Namrata\%20Goswami\%20USCC\%2025\%20 April.pdf

J, C. R., \& Majid, M. (2020). Renewable energy for sustainable development in India: current status, future prospects, challenges, employment, and investment opportunities. Energy,Sustainability And Society, 1020.

Kalam, D. A. (2013). Space Solar Power, Key to a Livable Planet Earth. Retrieved from http://space.nss.org/2013isdc-video-dr-abdul-kalam-space-solar-power-key-to-a-livable-planet-earth/

Lolla, A., Yang, M., \& Vats, G. (2021, May 20). Ember. Retrieved June 15, 2021, from global-electricityreview-2021: https://ember-climate.org/global-electricity-review-2021/g20-profiles/india/

Mankins, J. (2012). SPS-ALPHA: The First Practical Solar Power Satellite via Arbitrarily Large PHased Array. California: Artemis Innovation Management Solutions LLC.

Mankins, J. C. (1997, August 4-10). A fresh look at space solar power: New architectures, concepts and technologies. Volume 41, pp. 347-359.

Mankins, J. C. (1997). A Fresh Look at Space Solar Power:New Architectures,Concepts and Technologies. IAF97-R.2.03, 38th International Astronautical Federation, 10-12.

Mankins, J., \& Kaya, N. (2011). The First International Assessment of Space Solar Power: Opportunities, Issues and Potential Pathways Forward. Washington, DC: National Space Society.

National Security Space Office. (2010). Space-Based Solar Power As An Opportuinity for Strategic Security. National Security Space Office.

National Space Policy Secretariat, Cabinet Office. (2020, June 30). www8.cao.go.jp. Retrieved June 16, 2021, from https://www8.cao.go.jp/space/english/basicplan/2020/abstract_0701.pdf

Oda, M. (2004). Solar Power Satellite and its technical Challenges. Japan Aerospace Exploration Agency (JAXA), 6.

Power, G. o. (2021, April 30). Power Sector at a glance ALL INDIA. Retrieved June 15, 2021, from Government of India Ministy of Power: https://powermin.gov.in/en/content/power-sector-glance-all-india

Sangeeta DebBarmana, S. G. (2020). A Review:Space Based Solar Power(SBSP) in development of Smart city. International conference on Recent Trends in Artificial Intelligence, IOT, Smart Cities \& Applications (ICAISC-2020), 4.

Tarantola, A. (2015). Scientists make strides in beaming solar power from space. engadget, 857-861. 